Boards, has been issued to members of the medical profession by the Minister of National Service. The memorandum has not appeared a day too soon. It points out that a properly drawn certificate may be of great assistance to a Board, and that such a document is sure to receive full consideration. A good certificate should state name, age, and address of patient; date of last personal examination; length of time the patient has been personally known to the certifier; what diseases the latter has attended him for; the patient's present physical condition; and the name, address, and qualifications of the certifier. Particular care should be taken to avoid any expression of opinion as to the man's fitness or unfitness. for Military Service, which is a matter for the Board to form an opinion upon. Thus, it is one thing to certify that a man's sight is $1 / 10$ normal, and quite another to state that he is thereby unfitted for Service. A good certificate confines itself to matters which have come under the practitioner's personal knowledge. If reference be made to other matters not within the certifier's cognizance that fact should be made plain. For example, a certificate of epilepsy may be given, although the practitioner has never seen the patient in or immediately after an epileptic fit. The statement, in fact, is based upon nothing stronger than the man's word that he is subject to convulsive seizures. To put the matter briefly, a medical man who is called upon to give a certificate should regard himself as an impartial witness and not as an advocate or a judge.

\title{
Eyelashes in the Anterior Chamber
}

The Lancet (January 19, 1918) comments on an article by Cantonnet in the Progrès Médical (date not given) referring to the presence of eyelashes in the anterior chamber as a war injury, and gives the details of diagnosis and surgical treatment. Apparently Cantonnet is referring to cases in which the lashes have found their way into the chamber as the result of an explosion of a projectile, but without a definite wound. "It is difficult to understand" says the Lancet, " how a body so supple, long, and light as an eyelash can be torn from the eyelid and driven through the cornea to the iris. If at the same time a lesion, such as traumatic cataract, is produced, indicating the entrance to the eye of a comparatively large body, it is easy to imagine that in its passage it may have detached an eyelash and carried this with it. But when there are only punctiform specks on the cornea, without proof of any penetration, it is difficult to understand how the lashes can have penetrated." We are not so sceptical as our contemporary seems to be, but all the same this is an interesting subject on which we do 
not recollect to have seen any observations in British journals. We should welcome any communications on the penetration of eyelashes as a war injury.

\section{Records of Visual Acuity}

The Deputy Commissioner of the New York Department of Labour, part of whose work it is to determine the amount of compensation to be paid to claimants for losses in vision, writes to the American Journal of Ophthalmology pointing out that the scale he adopts is based 'upon such and such a percentage of loss.' If figures reach him as 20/20 he takes it that the man has 100 per cent. of vision; if $20 / 40$ that he has 50 per cent. of vision; and so on. He often receives reports from oculists, however, who do not work at a distance of twenty feet, and he then finds it most confusing to determine compensation on a percentage basis. $\mathrm{He}$ requests oculists in filling up the reports always to state specifically the percentage of loss of vision. In a note appended to the Deputy Commissioner's letter the Editor points out that the percentage scale has come into almost universal use in statistical studies. As applied to records of visual acuity it is easier to read and to print, and is indeed superior in all ways except that we are not accustomed to the method. "If the change made necessary the renumbering of our test-cards it would be an advantage, for they would be numbered more accurately."

\section{Eye Risks in Industrial Occupations}

In 1916, a survey of some seventy representative industries in the City of Buffalo was undertaken by the National Committee for the Prevention of Blindness (130, East Twenty-second Street, New York), and a book on "Eye Hazards in Industrial Occupations" has grown out of that inspection. An attempt has been made in the book to cover the entire field of risks to the eyes incurred in occupations in the United States, and a most interesting compilation is the result. The work bears the name as author of Gordon L. Berry, field secretary of the National Committee. Lieut. Thomas P. Bradshaw, U.S. Army, formerly technical assistant to the Director of the American Museum of Safety, has co-operated with $\mathrm{Mr}$. Berry. In the Buffalo examinations professional assistance was given by Drs. Ellice M. Alger (New York), Nelson M. Black (Milwaukee), Colman W. Cutler (New York), Francis E. Fronczek (Bufialo), Harold Giftord (Omaha), Franklin C. Gram (Buffalo), and F. Park Lewis (Bufialo). The contents of the book are extremely 